\title{
Commercial Explosives Controlling in Indonesia
}

\author{
Kasmen \\ Indonesian Police Headquarter, Div. of \\ Public Service \\ Jakarta, Indonesia \\ E-mail:kasmen_ali@yahoo.com
}

\author{
Sudarsono Hardjosoekarto, \\ Azhar Kasim
Faculty of Administrative Science Universitas Indonesia Depok, Indonesia

\begin{abstract}
Controlling is a continuously process. The scope of monitoring includes everything, especially for something that is inherently dangerous, such as commercial explosives. This study aimed to analyze the supervision of commercial explosives in Indonesia and developed the concept of supervision. This study is an action research using the app Soft Systems Methodology (SSM). Data were collected by in-depth interviews, informal discussions, and focus group discussion. This research has limitation about research period that did until 2016. The results showed that in exercising oversight of commercial explosives still have some obstacles such as low capacity of inspectors, lack of coordination, and a lack of effective oversight mechanisms. Changes in the Supervisory Team status become Supervisory Board proposed as one solution to optimize the supervision of commercial explosives. In the short term, optimization of supervision of commercial explosives can be realized by increasing the capacity of inspectors and coordination among relevant agencies. This research has contribution to develop controlling theory at every level of management.
\end{abstract}

Keywords-controlling; soft system methodology; commercial explosives

\section{INTRODUCTION}

Controlling is a continuously process $^{1}$. In this context, performance review process is not only done in one time, but sustainable. Time to conduct surveillance relies on work culture and policies of managerial ${ }^{2,3}$. The main purpose of the controlling is correcting action resulting in increased performance or revision of the plan has been set $^{4,5}$.

Like the other concepts, the concept of controlling had been developed. Vuko and Ovjan identified the development of controlling concept during the period 1970 to 2010. At first, the controlling is seen to function as an information provider. Then, the control concept developed not only limited to that, but it is also seen as a resultsoriented control. Furthermore, supervision is seen as a function of coordination. The concept of controlling does not stop there, but also controlling as a tool intended to create new values. It was only in the early 21th century, controlling is positioned as a guarantee of rationality supervision of management functions. ${ }^{6}$

By looking at the development of controlling concept above, it can be said that the surveillance covers everything. Supervision is applied at all levels of management, functions, and each unit or department. In public sector organizations, controlling is applied to provide excellent service to the community. Moreover, there is the scope of public services that are dangerous if not monitored, such as commercial explosives.

Efforts to support the development of particular economic sectors over challenged supervision of commercial explosives ranging from aspects of 
regulation, governance, to the structure of social relations. The existence of the conflict of interest of various stakeholders ranging from policy makers, supervisory authorities, to the businesses of commercial explosives increased the complexity of the issue. This complexity can refer to The New institutionalism in Economics and Sociology (NIES), which explains the existence of three institutional levels, namely the level of macro, meso, and micro. ${ }^{7}$ At the macro level there are institutional environment that has a role in regulation. The role governments have authority in the life of the nation. At the meso level, there is a collective action and monitoring \& enforcement agencies conducted supervisor. At the micro level there is decoupling and compliance.

Regulatory oversight of commercial explosives is now deemed to have been less relevant. This is because the regulations or laws governing the lodging of explosives recently created at the beginning of the independence of Indonesia. Among these regulations is the Explosives Ordinance (State Gazette 1893 No. 234), which was last modified in 1931 into the State Gazette No. 168 on the Entry, Ownership, Manufacture, Delivery and Use of Explosives. Then at the beginning of independence of the Republic of Indonesia issued Law No. 8 of 1948 on registration and licensing Use of Firearms, where the notion of firearms also included explosives and objects containing explosives. Legal sanction is regulated in Emergency Law No. 12 of 1951. Then the most advanced surveillance rules exist in the Government Regulation in Lieu of Law No. 20 of 1960 on Licensing Authority granted under Legislation on Firearms.

In terms of governance oversight, there are several agencies that play a role to supervise. In addition to the Ministry of Defence and the Police, other agencies involved are the Ministry of Trade, Ministry of Energy and Mineral Resources, Ministry of Finance, as well as several ministries and other institutions. Some challenges such as the importation of explosives surveillance without complete documents, blasting at the mine site illegal (illegal mining), blast fishing (illegal fishing), smuggling explosives, and so forth, coloring duties and responsibilities of the oversight agencies.

Then in terms of the structure of social relationships, problems arise on the relationships between businesses. From this relation it is possible that some cases of explosives from production to the use of commercial explosives. Some examples of cases that arise are businesses that do not have an operational license, the theft of explosives, the abuse of the use of explosives that are not in accordance with its allocation, and so forth.

With the above conditions, controlling effectiveness of commercial explosives is a challenge for administrators. Related to this, it needs an approach that can be applied in a regulatory process. Cornel \& LaviniaMaria describes the stages approach to the regulatory process, which is developing a targeted, analyzing the current site, reflecting the results of the current-state analysis using benchmarks, deriving the need for action using best practices, and drawing up the implementation plan. ${ }^{8}$ Challenges do not stop here, as to whether the control can be implemented is a next question. In this case, the opinion of Neda and Vanja can be considered that the need for processing of various targets of data and information, analytical judgment and 
appraisal, strategic and operational analysis and informations, and a transparent reporting system. ${ }^{9}$

Of the various explanations above, the complexity of the problems in the supervision of commercial explosives is quite visible. Therefore, this study aimed to analyze the supervision of commercial explosives that margin of safety and economy factors. This study refers to the theory of NIES. Ultimately, this research also explains the development of the controlling concept that combines theoretical study with empirical facts. That's because the use of the application of soft systems methodology in this study, which indicates the dual imperatives, namely besides oriented problem solving, research is also oriented towards research interest.

\section{RESEARCH METHOD}

This study is an action research study that uses the application of soft systems methodology (SSM). In this study, data were collected through interviews and in-depth discussions with various stakeholders from different institutions associated with the controlling activities of commercial explosives and with the leadership of a business entity engaged in the business of commercial explosives as well as the end users of commercial explosives. This research collected data publication before 2016. Then, the data were analyzed with reference to the phasing performed on Seven Stages of SSM developed by Checkland and Scholes. ${ }^{10}$

The first step in terms of data analysis is the problem considered problematic situation. At this stage, efforts to find a situation in unstructured problems. Then the second stage exspressed be a problem situation. At this stage structuring problem situations with all elements linked to form the structure of the problem situation. The situation is expressed in a rich picture, which must be answered: structure, process, climate, people, issues expressed by these people, and conflict. The next stage is the third root of purposeful activity definitions of relevant systems. The analysis conducted in this phase is to determine the root definitions of the relevant system, to portray the transformation process and situational changes are made in the real world. The fourth stage in the form of conceptual models of the systems (holons) named in the root definition. This phase is carried out to prepare a conceptual model that is prepared to indicate the purpose of the system is necessary. The problems and the main task of a rich picture taken form the basis for defining what is called 'the relevant system'. The fifth stage is comparison of models and real world. Furthermore, the sixth stage is the changes: systematically desirable, culturally feasible, which was to determine feasible and desirable change by considering systematically desirable and culturally feasible. The last stage is action to improve the problem situation.

\section{RESULTS}

This section explains results of research. There are explanations about problematic situation, relevant system, comparison of relevant system to problematic situations, and developing supervision concept.

\subsection{Problematic Situations of Commercial Explosives Control}

In the governance structure of commercial explosives controlling, there are various stakeholders involved and the roles, norms, and values that differ according to the scope of the stakeholders are located. At the macro 
level, there are the House of Representatives and the President whose role is to make laws and set policies related to explosives. They must abide by the constitution as the existing norms at this macro level.

At the meso level, role of Explosives Supervisory Team is overseeing accordance with their respective authorities. One of the policies that form the basis of the division of authority is the President of the Republic of Indonesia Decree No. 1251999 About Explosives. According to the policy, the Ministry of Defence is the coordinator of the Supervisory Team. In implementing its duties and functions, the Ministry of Defence has to do coordination with other agencies.

Coordination with militer headquarters includes the supervision and control of production, procurement, storage, distribution, export, use and destruction of explosives for military purposes and explosives for industrial purposes (commercial). Then coordination was also carried out by the Police Headquarters of the Republic of Indonesia in terms of supervision and control activities of production, procurement, storage, distribution, export, use, transfer and disposal of explosives for industrial (commercial). Coordination is also implemented by departments/ministries responsible for health and industry, in terms of determining the type of chemicals that can be categorized as a hazardous material, the raw material of explosives.
In addition, coordination is also done by departments/ministries responsible for trade in terms of supervision of trade and distribution of explosives. Furthermore, coordination is also done by departments/ministries responsible for finance in terms of fulfillment of customs obligations associated with the export/import of explosives.

At the micro level, there is the role of businessmen from the activities of production, distribution, warehousing, to the use of commercial explosives. The businesses must abide by the conditions set by the relevant government commercial explosives. The involvement of various stakeholders in the controlling institutional of commercial explosives led to various problematic situations. Based on the interview, problematic situations can be classified according to institutional levels. At the macro level, the problematic situations that arise regarding the effectiveness and efficiency of existing policy, the relevance of legislation related to the supervision of commercial explosives, and changes in legislation related to oversight. At the meso level, which appears problematic situation is still weak oversight, lack of supervisory capacity, and lack of coordination related stakeholders. While at the micro level, the problematic situation is high costs economic for businesses running their business. The problematic situations overview is presented in the form of rich picture. 


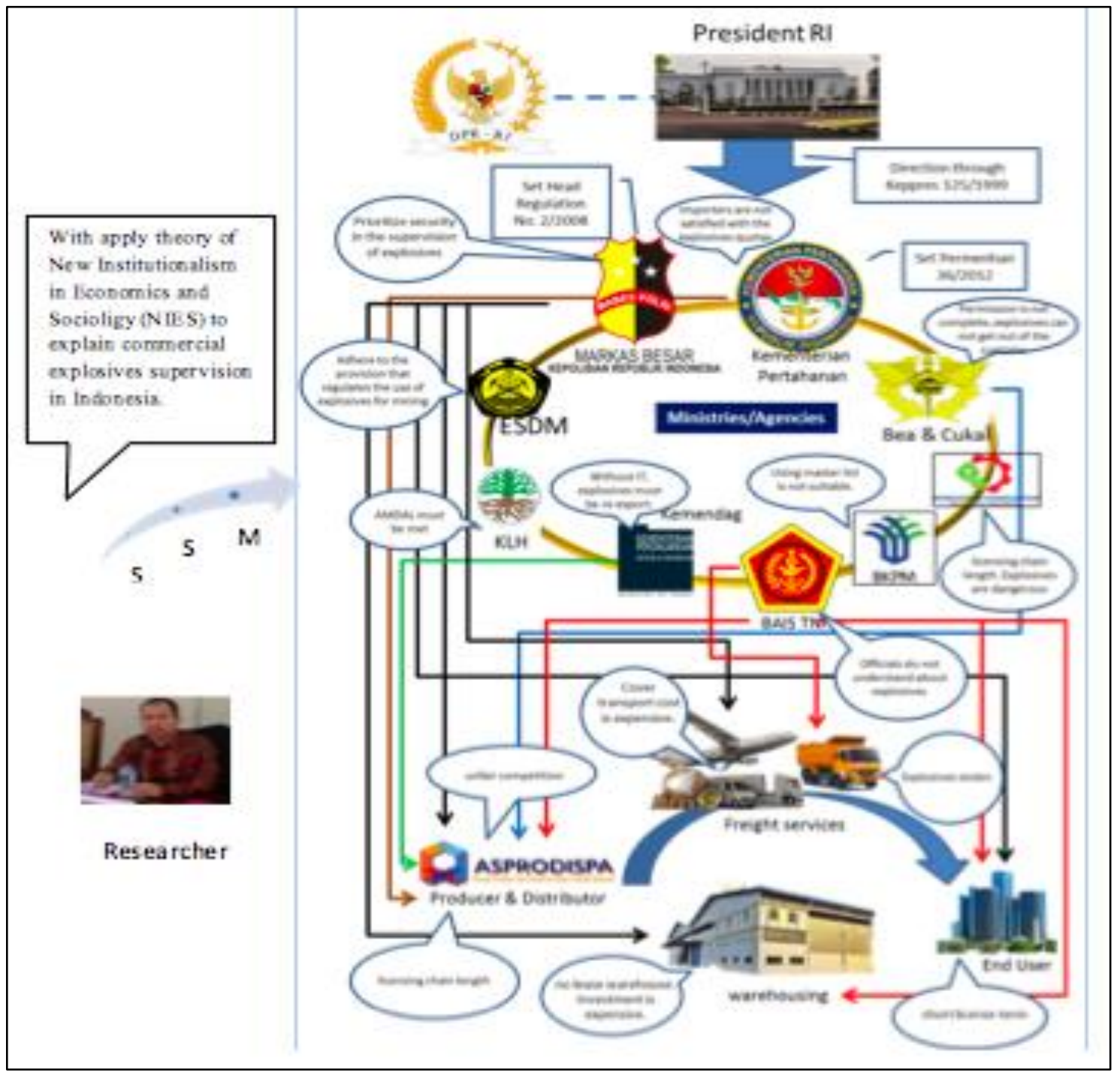

Figure 1. Rich Picture

\subsection{Relevant System for Commercial Explosives Control}

After a problematic situation regarding the controlling of commercial explosives is identified, determining in advance the ideal system or the relevant supervision starts the analysis process. In this case, the relevant system related to the implementation of supervision of commercial explosives is a "system that is owned and operated by the stakeholders at the level of meso
(Explosives Supervisory Team) in order to achieve effective monitoring and implementation supervision of commercial explosives through the optimization of the role of the Supervisory Team Materials Commercial explosives to revitalize the supervision of commercial explosives with a margin of safety and economy ". The relevant system is then analyzed using analysis CATWOE. 
Table 1. CATWOE

\begin{tabular}{ll}
\hline $\begin{array}{l}\text { Customers } \\
\text { Actors }\end{array}$ & $\begin{array}{l}\text { Stakeholders of all levels } \\
\text { Explosives Supervisory Team }\end{array}$ \\
Transformation & Less effective supervision becomes more effective \\
Weltanschaung & $\begin{array}{l}\text { Optimization of role from Explosives Supervisory } \\
\text { Team }\end{array}$ \\
Owner (s) & $\begin{array}{l}\text { President } \\
\text { Stakeholders who do not want the act collectively } \\
\text { for overseeing commercial explosives }\end{array}$
\end{tabular}

CATWOE analysis showed identification of the stakeholders involved in the transformation process. ${ }^{11}$ In this analysis identified who the customers or beneficiaries of the transformation process, actors or who is doing the transformation, transformation or conversion process from input to output, weltanschauung worldview or what makes the process of transformation into a meaningful, owner or any person who can stop the transformation, and environement constraints or elements outside the system that affect the process of transformation. CATWOE analysis is presented in Table 1.

The relevant system is then described in a conceptual model that includes activities interconnected. The conceptual model was developed Figure 3 illustrates the conceptual model activities that support for the realization of commercial explosives supervision effective.

Activities in the conceptual model begin with a referral from the president to the relevant agencies to supervise the activities associated with commercial explosives. Directives of the president can take the form of government regulations, presidential decrees, or other regulations under its authority. In those directives, there is a division of tasks, functions and powers of the ministries/agencies that received directives from the President. Once the relevant ministries/agencies receive referrals from president, the direction is usually accompanied by demands to create a rule instance at the level of ministries/agencies concerned. For example, a rule can be derived ministerial regulations. Then, the derivative rules followed by the standard operational procedure (SOP).

Table 2. Activities of Relevant System

\begin{tabular}{ll}
\hline Activity 1 & President gives direction through regulation to relevant ministries or agencies. \\
\hline Activity 2 & Ministries or agencies formulates derivative regulation appropriate each authority. \\
\hline Activity 3 & Ministries or agencies formulates SOP \\
\hline Activity 4 & Ministries or agencies empower human resources as program implementator. \\
\hline Activity 5 & Implementators implement derivative regulation and SOP. \\
\hline Activity 6 & Implementators optimize various resources. \\
\hline Activity 7 & Implementators supervise implementation of derivative regulation and SOP. \\
\hline
\end{tabular}




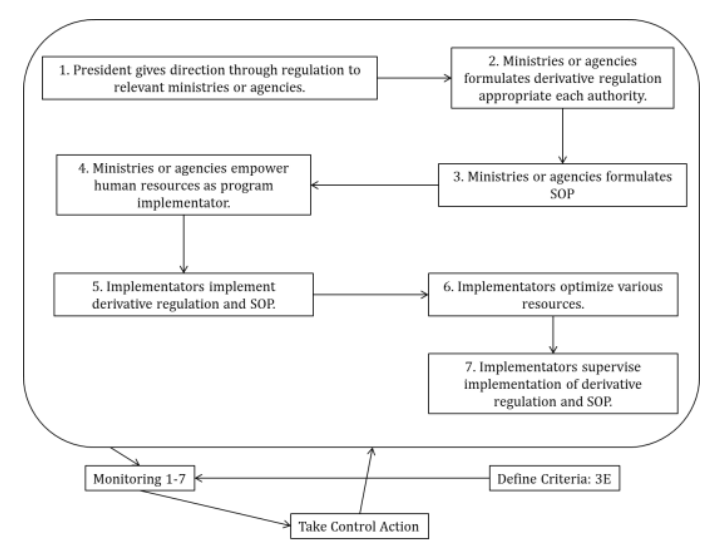

Figure 2. Conceptual Model

The next activity that occurs in the conceptual model developed is the deployment of human resources (HR) conducted by the relevant ministries or agencies. This is implemented as part of the mobilization of resources, besides the budget. HR has been given the task to carry out the task to implement the various provisions of the derivatives rules and SOP that has been set. Then, in the process of supervision, there are activities to optimize a variety of resources owned by the relevant agencies.

Success or failure can be measured through a conceptual model of the three criteria. The first criterion is the efficacy, the role optimization of Supervisory Team. Second, is efficiency that using minimum resources. Third, effectiveness meaning this model is successful if the achievement of the implementation and monitoring of effective policies.

\subsection{Comparison of Relevant System to Problematic Situations of Commercial Explosives Supervision}

Normatively, policies have to be implemented. There are six steps in the policy shaping process. These six steps are namely agenda setting, policy formulation, policy implementation, policy evaluation, policy change, and policy termination. ${ }^{12}$ Thus, policy implementation is the next part after implementing regulation at the ministerial level and its SOP has been created. In order for the policies implementation run optimally, it is necessary to supervise the implementation of the policy.

Supervision is more dominant fixed by the policy implementation phase. It was due to the implementation of the policy in principle is a way for a policy can achieve its objectives, no more and less. ${ }^{13}$ Although the planning was done so well, but it is not implemented, then the policy will be in vain. When the policy is not implemented, there are no evaluation results to provide feedback for future improvements to the policy. Therefore, it is often more dominant scrutiny attached to policy implementation. Referring to the concept, then the rules of derivatives at the ministerial level and its SOP will not mean anything if it is not implemented. Then, these implementations will be useless if not monitored for their potential to commit a violation of the stakeholders implement the derivatives rules and SOPs.

On the concept of public policy oversight explained supervision in the context of public policy knowing the aspects that determine the success of policy implementation can do implementation. In other words, monitoring the implementation of the policy can be done by monitoring aspects of the determinants of success, namely standards and policy goals, resources, policies, communication between organizations involved in it, the characteristics of the implementer, economic, social, and political, and attitude executing. 
In practice, some aspects are critical factor for successing of commercial explosives supervision. However, these aspects still have shortcomings that need to be repaired. In addition to the problem of coordinating the Supervisory Team, the other dominant issue that arises is the monitoring mechanism and the capacity of supervisors. A monitoring mechanism related to supervisory procedures. The supervisory capacity with regard to the performance of supervisors in monitoring activities related to explosives.

Related to the monitoring mechanism, the practice of its implementation showed that the surveillance mechanism must still be improved. For example, the stakeholders in the micro level require routine patrol officers conducted mainly in the warehouse of explosives. It also calls for a common perception of the supervisor in monitoring. Then, in addition to the monitoring mechanism, other issue is improving supervisory capacity. Supervisors are general nature. In other words, do not point to any one of the ministries that are part of the Supervisory Team.

Then, the revitalization of commercial explosives supervision is required to change the status of the Explosives Supervisory Team become Explosives Supervisory Board. The status change can be an alternative solution that is more effective supervision of explosives. To be ideal, status of Explosives Supervisory Board should be directly under the President. Thus, responsibility of explosives supervision is directly under authority of the President. The hope, burgening power of the Board of Supervisors becomes stronger when compared to its status just as the Supervisory Team.

Supervisory Team status changes into the Supervisory Board directly under the President is feasible through the establishment Explosives Act. The law can be brought article mentions that the supervisory authority can be implemented by Explosives Supervisory Board Explosives are directly responsible to the President. To elaborate the duties, responsibilities, authorities, and so forth of the Explosives Supervisory Board, can be regulated in a government regulation.

Revitalization supervision of explosives can also be implemented through capacity building superintendent. This is particularly important given the low capacity of supervisors in monitoring explosives. With the increase in the capacity of supervisor of explosives, the regulatory process will be effective. The impact, the provisions relating to explosives can be observed by operators in carrying out their business activities.

Desire for increased supervisory capacity should be realized easily. It was because of the policies that exist today are very supportive for increased supervisory capacity. In fact, this policy came from the helm of the state, namely the President. With the mental revolution policy set by the President, it does give a positive meaning for improving the capacity of supervisors. In addition, the government is focusing realize bureaucratic reform policy. One aspect of target of bureaucratic reform is the reform of personnel resources. In other words, if there are efforts to improve the regulatory capacity of the explosives, then it is in accordance with the policy of bureaucratic reform that is being intensively conducted by the government.

Increasing the capacity of the controller can be done in various ways. One possible way is to provide training to improve the skills and knowledge of supervisors in monitoring explosives. 
By doing so, inspectors can provide a solution to the various problems that arise during the process of supervision do.

\subsection{Developing Supervision Concept}

The development concept of supervision is the other result of applying SSM application. There are steps taken to produce a development concept of supervision, namely (1) the foundational theories, (2) the foundational theoris and empirical facts as basic to formulate research interest, and (3) research contribution.

The first concerns the foundational theories. This study examines and explains the basic theories used. These theories include surveillance in public policy, monitoring the policy of explosives, the institutional framework, and learning about the setting of explosives from other countries. These theories filtered and adopted to formulate new concepts related to the supervision of commercial explosives.

Then, the study found empirical facts that can enrich the concept of supervision of commercial explosives. Therefore, the second part of the framework of research interest is the combining the foundational theories and field findings (empirical facts). Field findings (empirical facts) are the intellectual properties that are very valuable for the development of concepts that can be done in accordance with the conditions occur. Furthermore, a review of foundational theories with empirical facts produces a research contribution. The results are the third part of the framework of research interest. Research of this contribution is the result of the development of the concept that is the goal of research-oriented research interest. Hopefully, the result of the development of this concept may be new knowledge, so that it can be adopted both theoretically and practically.

By adopting NIES theory, formulated three levels under the supervision of commercial explosives. The third level is the level of macro, meso, and micro. Each level has its own characteristics, but by no means isolated from one another. Macro level is the regulatory aspect (regulation aspect) focusing on formulation and policy directions. Policy formulation is a process performed by actors at the macro level. With the formulation of policy, the legal framework and supervision of explosives became apparent. Then, another thing to be the focus of the regulatory aspects at the macro level is the policy direction (direction). The role of actors at the macro level is not only formulates policies, but also steer policy clearly to the institution in question.

Meso level is controlling governance. In this stage, the stakeholders in controlling the level of governance attached to it two roles, that of collective action and monitoring and enforcement. Collective action focuses on communication and coordination activities. With the communication and effective coordination, the division and the implementation of the task will be more obvious. Communication and coordination activities proposed to be the focus of this aspect of collective action is derived from empirical experience of supervision of explosives.

The second role related to monitoring and enforcement, the stakeholders at the level of controlling governance perform supervisory activities adopted from some concept of the regulatory process, namely the development of the concept of supervision put forward Vuko and Ovjan, approach to oversee the 
proposed Cornel and Lavinia-Maria, and function supervision described Neda and Vanja. With reference to the three concepts suggested by experts monitoring the monitoring and enforcement role in controlling the level of governance aims to provide information, oriented on achieving results, facilitate coordination, creates new value, and as a guarantee of the rationality of a management process. The destination refers to the opinion expressed Vuko and Ovjan.

In order to achieve the above objectives, the activities or measures supervisory approach as set forth Cornel and Lavinia-Maria to do, which is developing a targeted, analyzing the current site, reflecting the results of the current-state analysis using benchmarks, deriving the need for action using best practices, and drawing up the implementation plan. For supervision sustainability, the opinion of Neda and Vanja be adopted, namely the need for processing of various targets of data and information, analytical judgment and appraisal, strategic and operational analysis and informations, and a transparent reporting system.

In the implementation of monitoring and enforcement, a combination of three expert opinions provides value to the development of the concept of surveillance. Supervision is not only seen as a guarantee of the rationality of a management process to oversee implementation of the policy or program in order to obtain the result set, but also provide a new perspective for the supervisors that the supervision must be a proposition provider of information, improve coordination, and create new value. With this perspective, the supervision is not only seen as a formality of the implementation of management functions, but give effect to the implementation of sustainable policies or programs.

At the micro level, there is a structure of a business relationship. The stakeholders at the level of this interaction and transactions in order to meet two aspects, namely the decoupling and realize avoid compliance. In the implementation of the structure of this business relationship, business operators are the objects of various rules set forth by actors on the macro level. The form of arrangement for business operators is the conditions that must be satisfied in doing business (requirement) and penalties if businesses commit the offense, the form of the arrangement. Technically, the monitoring carried out by the stakeholders who are in controlling the level of governance that is already mandated by law.

Although the stakeholders at the micro level are object of the rules, but it does not mean that these stakeholders can't participate in supporting the revitalization explosives supervision. In the context of the implementation of open government, the stakeholders have the right to express the aspirations of the stakeholders at the macro level. For example, businesses feel that they are not effective against the rules, so that they are calling for a revision of the rule does to those at the macro level.

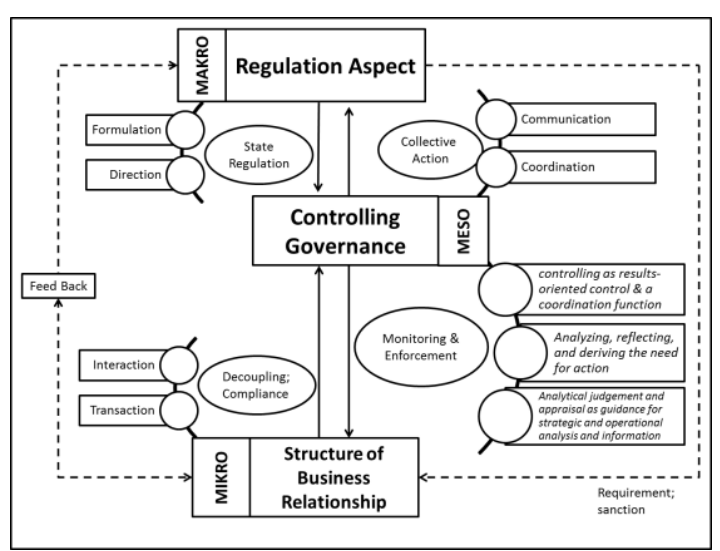


Figure 3. Result of Developing Supervision Concept

The result of the supervision concept development is shown in Figure 3. These results may provide new knowledge to be applied in other oversight mechanisms that have the appropriate context. In general, the suitability occurs in the realm of public sector organizations.

Organasisasi public sector as a stakeholder who has the authority to administer public services, it is necessary to consider some aspects so that public services provided to satisfy stakeholders. In the framework of that goal, the implementation of various policies and programs deemed necessary support from other stakeholders. In other words, public sector organizations do not always bear the 'burden' of public service obligations. In relation to it, this study proves that the government's cooperation with the other stakeholders in this case is a private sector organization are important, both in terms of providing feed back or attitude of compliance and avoid decoupling.

\section{CONCLUSION}

Controlling of commercial explosives has some obstacles such as low capacity of officers, lack of coordination, and a lack of effective oversight mechanisms. It remains a challenge to be resolved by the relevant agencies. Changing status of the Supervisory Team to Supervisory Board is expected to become as one of the solutions for the effective supervision of commercial explosives.

The status changing can be applied through the establishment Explosives Act. In other words, there is a setting in the Explosives Act proposed that the supervisory authority of explosives under the authority of the Supervisory Board Explosives are directly responsible to the President. To elaborate the duties, responsibilities, authorities, and so forth of the Explosives Supervisory Board, can be regulated in a government regulation.

For the short term, the optimization of the Explosives Supervisory Team can be implemented by increasing the capacity of employees. Thus, the agencies that have the controlling authority required performing a variety of programs for the improvement of skills and knowledge of its employees related to the supervision of commercial explosives. In addition, increasing the quantity and quality of coordination between the competent agencies to supervise the commercial explosives can also do it.

The results also provide novelty knowledge in the theory of public policy control that can be applied in researching problems of supervision of various commodities, supervision concept that has been developed can be used as a reference for analyzing the problems occurred, whether the problem is contained on the macro level related legislation or regulation set (regulation aspect), or at the level of meso as governance (controlling governance), or at the micro level on the side of businesses (structure of the business relationship).

\section{References}

1. Ettorchi-Tardy, A., Levif, M., \& Michel, P. (2012). Benchmarking: A Method for Continuous Quality Improvement in Health. Healthcare Policy, Vol. 7, No. 4, pp. 101119.

2. Ariely, Dan. (2000). Controlling the Information Flow: Effects on Consumers' Decision Making and Preferences. Journal of Consumer Research, Vol. 27, pp. 233248.

3. Vohs, Kathleen D., Baumeister, Roy F., Schmeichel, Brandon J., Twenge, Jean M., 
Nelson, Noelle M., \& Tice, Dianne M. (2008). Making Choices Impairs Subsequent Self-Control: A Limited-Resource Account of Decision Making, Self-Regulation, and Active Initiative. Journal of Personality and Social Psychology, Vol. 94, No. 5, pp. 883898.

4. Rajagopal, Ananya Rajagopal. (2008). Team Performance and Control Process in Sales Organizations. Team Performance Management: An International Journal, Vol. 14, Iss: 1/2, pp.70 - 85

5. Ogbo, Ann I. \& Ukpere, Wilfred I (2014). The Impact of Effective Inventory Control Management on Organisational Performance: A Study of 7up Bottling Company Nile Mile Enugu, Nigeria. Meditteranean Journal of Social Science, Vol. 5, No. 10, pp. 109-118.

6. Vuko, Tina \& Ovjan, Ivica. (2013). Controlling and Business Efficiency. Croatian Operational Research Review (CORR), Vol. 4, pp. 44-52.

7. Nee, Victor. (2003). The New Institutionalism in Economics and Sociology. CSES Working Paper Series. Department of Sociology, Center for the Study of Economy and Society, Cornell University, Ithaca

8. Cornel, Grigorut \& Lavinia-Maria, Grigorut. (2012). Controlling - A Usefull Tool for Top Management. Constanta Maritime University Annals, Vol. 18, pp. 305-308.

9. Neda, Vitezić \& Vanja, Vitezić. (2015). A Conceptual Model Of Linkage Between Innovation Management And Controlling In The Sustainable Environment. The Journal of Applied Business Research, Vol. 31, No. 1, pp. 175-184.

10. Hardjosoekarto, Sudarsono. (2012). Construction of Social Development Index as a Theorical Research Practice in Action Research by Using Soft Systems Methodology. Systemic Practice \& Action Research, Vol. 25, Issue 6, p493-509.

11. Checkland, Peter and Poulter, John. (2006). Learning for Action: A Short Definitive Account of Soft Systems Methodology and its use for Practicioners, Teachers and Students, John Wiley and Sons, Ltd, Chichester.

12. Lester, R. James \& Stewart, JR. Joseph. (2000). Public Policy. Wadsworth Thomson Learning 2nd ed.

13. Noruzi, Mohammad Reza. (2011). Policy Affairs and Policy Implementation Issues; How Policy Implementation Can Be Effective? Journal of Public
Administration and Governance, Vol. 1, No. 1, pp. 1-7. 